\title{
Simulation and Modeling of an Integrated Process Route for the Synthesis of Vinyl Chloride Monomer from Acetylene: Factorial Design Method and Artificial Neural Network
}

\author{
${ }^{1 *}$ Akintola, J.T., ${ }^{1}$ Ayoola, A.I., ${ }^{2}$ Abdulkareem, Y.T., ${ }^{3}$ Akintola, O.E., ${ }^{3}$ Etisioro, C.O \\ ${ }^{1}$ Department of Chemical Engineering, University of Lagos, Akoka, Nigeria \\ ${ }^{2}$ Department of Chemical Engineering, Lagos State University, Epe, Nigeria \\ ${ }^{3}$ Department of Statistics, Yaba College of Technology, Yaba, Lagos, Nigeria
}

\begin{abstract}
Vinyl Chloride gas is a nonirritating and colorless substance. It is usually colorless at a concentration lower than 3900 ppm $(10,000 \mathrm{mg} / \mathrm{m} 3)$. Vinyl Chloride is simply compressed to liquid for storage and shipping. At a concentration between 200 and 500 $\mathrm{mg} / \mathrm{m} 3$, a Sweetish odor of Vinyl Chloride may be detected. This research paper is focused on the simulation of an integrated process route for the synthesis of Vinyl chloride Monomer from Acetylene via Aspen Hysys Simulation as well as the Factorial Design of the experiment with MINITAB 17.0. Fit Regression and Artificial Neural Network were employed for the modeling of the responses. Molar flow rates of acetylene $(\mathrm{C} 2 \mathrm{H} 2)$ and hydrogen chloride $(\mathrm{HCl})$ predicts the conversions of acetylene and hydrogen chloride. A recycle unit is added to the process flow diagram and the maximum conversion of $\mathrm{C} 2 \mathrm{H} 2$ and $\mathrm{HCl}$ is found to be 99.90 and $99.80 \%$, respectively. Analysis of variance (ANOVA) gives the results of the statistical correlation between the independent variables and response variables. The simulation and modeling results reveal that the Artificial Neural Network model gives better prediction and analysis of the process route with correlation coefficient ( $R$ squared values) of $97.921 \%$ and $98.423 \%$ for the conversion of $\mathrm{C} 2 \mathrm{H} 2$ and conversion of $\mathrm{HCl}$, respectively compared to the Factorial Design Method model with $\mathrm{R}$ squared values value of $79.47 \%$ and $73.70 \%$ for the conversion of $\mathrm{C} 2 \mathrm{H} 2$ and conversion of $\mathrm{HCl}$, respectively.
\end{abstract}

Keywords: Vinyl chloride Monomer, Conversion, Aspen Hysys simulation, Factorial Design Method, Artificial Neural Network.

\subsection{INTRODUCTION}

\subsection{Vinyl Chloride}

Vinyl chloride (VC) is a nonirritating, colourless gas at standard temperature and pressure. It is generally odorless below $10000 \mathrm{mg} / \mathrm{m}^{3}$ (3900 ppm), but a sweetish odour may be detected by some sensitive individuals between 200 and $500 \mathrm{mg} / \mathrm{m}^{3}$. The gas is liquefied under pressure with ease and is frequently stored or shipped as a liquid [1]. Vinyl chloride is highly stable in the absence of sunlight or oxygen. Above $400{ }^{\circ} \mathrm{C}$, it dissociates into acetylene and hydrochlorine. In the atmosphere, VC reacts with hydroxyl radicals and ozone, ultimately forming formaldehyde, carbon monoxide, hydrochloric acid and formic acid. On the basis of measured reaction rates with hydroxyl radicals and their concentration in air, it is estimated that the half-time of VC in the atmosphere is about 20 hours [2]. Vinyl chloride, essentially all of which is used to synthesize poly (vinyl chloride) and vinyl chloride copolymers, is the chief tonnage organochlorine compound produced, with the exclusion of its precursor, ethylene dichloride. Vinyl chloride monomer (VCM) finds its chief sources in order of significance from VC production plants, polyvinyl chloride (PVC) polymerization infrastructures, and plants where PVC products are fabricated. Minor sources include storage and handling facilities for VC and PVC and plants producing ethylene diamine or ethylene dichloride. VC emissions have been reported from municipal landfills in the United States, but the precise source of emission is uncertain and 
systematic survey data are unobtainable [1]. Vinyl chloride monomer finds good applications in medical equipment, building materials, packaging materials, electronics equipment, etc. Roughly 5 million tonnes of $\mathrm{VC}$ were produced in the entire region of Europe in 1981. The levels of emission from VC and PVC production plants and facilities depend upon the processes and control technology engaged. The implementation of the best existing technology can reduce emissions below $1 \%$ of production volume, nevertheless emissions from facilities in some nations surpass this value [2]. For the acetylene-based process, Vinyl chloride has been prepared since the early 1930s by the reaction of hydrogen chloride with acetylene is presented in (1) [3]:

$$
\mathrm{CH} \equiv \mathrm{CH}_{(g)}+\mathrm{HCl}_{(g)} \rightarrow \mathrm{CH}_{2(g)}=\mathrm{CHCl}_{(g)}
$$

The reaction occurred in the vapor phase, in the presence of a catalyst containing mercuric chloride supported on active carbon, at temperatures between 97 and $177{ }^{\circ} \mathrm{C}$ depending on the age and activity of the catalyst. Due to ageing of the catalyst, it activity drops; and to sustain the reaction rate, the temperature is elevated [3]. The yields obtained from this process is within $80 \%$ to $95 \%$, with a by-product is 1,1 -dichloroethane. The process is highly desirable as the reaction conditions are mild, it is a one-stage process, the stoichiometry is favorable and heat is not supplied since the reaction process is exothermic [3].

\subsection{Factorial Method, Artificial Neural Network And Simulation}

Factorial and fractional factorial designs are usually used as experimental strategies to evaluate the impact of several factors on a response process variable [4]. Total randomization of the experimental runs is often not practical when it is hard to alter the levels of some of the factors [4]. Factorial design experiments include concurrently more than one factor and each factor is at a minimum of two levels. Numerous variables or factors have simultaneous effect on the behavior under investigation in factorial design experiments. Hence, the alchemist is concerned with the main and interaction effects amongst dissimilar and independent variables or factors. Factorial experiment is said to be "symmetrical" if the number of levels for all factors are the same, and "mixed" if the number of levels of each of the factor are different. Considering the significance of factorial design methods, they are said to be more effective than experiments with one-factor-at-a-time and it is essential in presence of interactions to circumvent deceptive inferences. Factorial design methods also allow the influence of an independent variable to be projected at numerous levels of the other independent variables, giving rise to valid deductions over a variety of experimental conditions [4].

Artificial Neural Network (ANN) has over the years made a remarkable contribution to various fields including engineering and technology. As such, it has brought about advancement in the fields [5]. Artificial neural network is a modelling technique which simulates the operation of the brain and nervous system [6]. It is an information processing system that does specific function similar to the biological neural network [7]. In this pattern, the main element is the innovative structure of the information processing system that is composed of highly interconnected processing element working in unison to solve a specific problem. Artificial Neural Networks learn by example like humans do [8]. Artificial neural network is configured to do a specific work which includes data classification or pattern recognition through the process of learning. In biological systems, learning involves the adjustment of the synaptic connection that exists between the neuron [9]. Artificial neural networks are typically complex communication networks wired together from hundreds of simple processing unit or nodes. Each unit is a model of the neuron which sends off a new signal when it received strong and sufficient input signal from the other nodes which it is connected [8]. Hence, ANN resembles the brain in two ways. Firstly, the network acquires knowledge through the process of learning. Secondly, the knowledge is stored using the interneuron connection strengths which are the synaptic weights [10]. ANNs are applicable in quantifying nonlinear relationship between a model dependent and independent variables by means of iterative training of data obtained [11]. This is similar to conventional statistical model where error between model outs and corresponding measured values (training set) of a particular data set are minimized by adjusting the model parameters (such as connection weights) in the model calibration phase [12]. Performance of ANNs can be improved by developing the ANN models in a systematic manner which will address major factors, including the determination of adequate model inputs, data division and pre-processing, the choice of a suitable network architecture, careful selection of some internal parameters that control the optimization method, the stopping criteria and validation of model [13]. 
Process simulation defines the imitation of a real-time process that represents its operation over time. Simulation is often used with scientific modeling of chemical engineering processes or systems to give an insight of the behavior of the particular process or system. It displays the eventual real effects of substitute conditions and courses of action. Computer simulation of a chemical process models the process in a way it emulates a real-time process, usually on a pilot scale. Aspen HYSYS is a software package for computer simulation of chemical processes and useful in industries such as chemical, process optimization, bio-chemical, process control, wastewater treatment, pharmaceutical, petrochemical, oil and gas, etc. [14], [15].

\subsection{METHODOLOGY}

Vinyl Chloride Monomer was synthetized by simulating the process route presented in figure 1.0 with Aspen Hysys 8.8. The integrated route consists of addition of a recycle unit for recovering unreacted feed gases for further reaction in order to achieve $99.90 \%$ conversion for Acetylene and $99.98 \%$ conversion for hydrogen chloride from the reaction process, a cooling device for further cooling of the separator product and a column in order to obtain a stream of approximately $99.98 \%$ purity of the Vinyl Chloride Monomer. Factorial Method was used to design the experiment; Fit Regression of linear model and Artificial Neural Network were used to model and predict the responses (Hysys Simulation results).

\subsection{Process Route Description}

The integrated computer-simulated process for the synthesis of Vinyl Chloride from Acetylene is presented in figure 1.0. Within the process route, the reactant gases are mixed in a Feed mixer (B1) and then Compressed in (B1) for better interaction of the reactant gases. The compressed gases are fed into a Process conversion reactor (B3) where Acetylene is chosen as the base component and setting the default conversion to $90 \%$. The reactor top exit stream is cooled in a box cooler (B4) and Short column (B5) with top product recycled back to the chest of the reactor to achieve $99.90 \%$ conversion for acetylene and $99.89 \%$ conversion for hydrogen chloride. The bottom product is the VCM rich stream which exits at a low temperature of $-16.62{ }^{\circ} \mathrm{C}$ and heated in a heater (B6) in order to elevate the temperature to $25{ }^{\circ} \mathrm{C}$. The heat of reaction depicts that the reaction process is exothermic with the value $-2.4 \times 10^{4}$ $\mathrm{kcal} / \mathrm{kgmole}$. The exit stream from B6 is further sent to a component splitter (B7) to further separate the VCM monomer from other components (substances), hence achieving a mole composition of $1.00(100 \%)$ in the pure VCM stream. The equipment design parameter and experimental design values presented in tables 1.0 and 2.0, respectively.

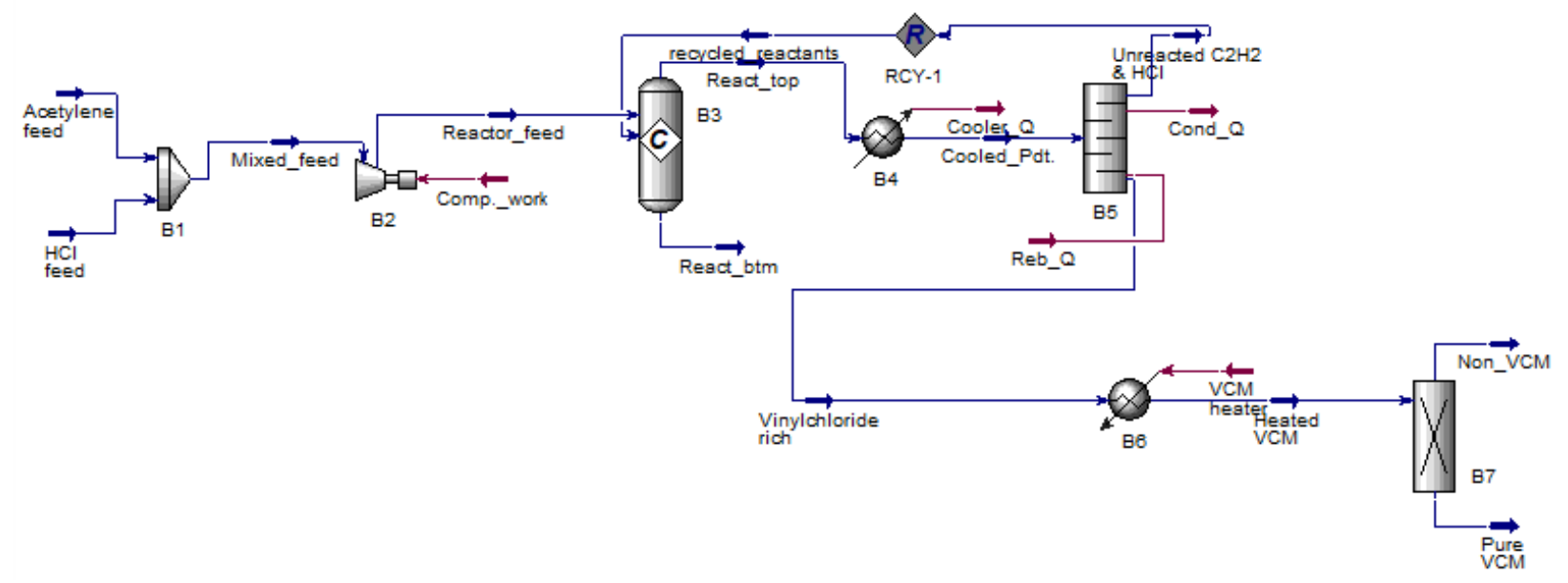

Figure 1.0: Integrated Computer-Simulated PFD for the synthesis of VCM from Acetylene 
International Journal of Advances in Scientific Research and Engineering (ijasre), Vol 6 (12), December -2020

Table 1.0: Equipment design parameter and value

\begin{tabular}{|c|c|c|c|c|c|c|c|}
\hline \multirow[t]{2}{*}{$\begin{array}{l}\text { Feed Mixer } \\
\text { (B2) }\end{array}$} & \multirow[t]{2}{*}{$\begin{array}{l}\text { elevation } \\
\text { (Base) (m) }\end{array}$} & $\begin{array}{l}\text { elevation } \\
\text { (Ground) } \\
\text { (m) }\end{array}$ & Diameter (m) & & & & \\
\hline & & 2.00 & 2.00 & & & & \\
\hline \multirow[t]{2}{*}{$\begin{array}{l}\text { Compressor } \\
\text { (B2) }\end{array}$} & $\begin{array}{l}\text { Adiabatic } \\
\text { head }(\mathrm{m})\end{array}$ & $\begin{array}{l}\text { Polytropic } \\
\text { head }(\mathrm{m})\end{array}$ & $\begin{array}{l}\text { Adiabatic eff. } \\
(\%)\end{array}$ & $\begin{array}{l}\text { Polytropic eff. } \\
(\%)\end{array}$ & Duty (kW) & $\begin{array}{l}\text { Capacity } \\
\left(\text { ACT }-\mathrm{m}^{3} / \mathrm{h}\right)\end{array}$ & $\begin{array}{l}\text { Delta P } \\
\text { (bar) }\end{array}$ \\
\hline & $1.300 \times 10^{4}$ & $1.330 \times 10^{4}$ & 85.00 & 86.971 & $195.2 \mathrm{~kW}$ & 3695 & 3.00 \\
\hline \multirow[t]{2}{*}{$\begin{array}{l}\text { Process } \\
\text { Reactor (B3) }\end{array}$} & $\begin{array}{l}\text { Delta P } \\
\text { (bar) }\end{array}$ & $\begin{array}{l}\text { Vessel } \\
\text { volume }\left(\mathrm{m}^{3}\right)\end{array}$ & $\begin{array}{l}\text { Liquid level } \\
(\%)\end{array}$ & $\begin{array}{l}\text { Liquid } \\
\text { volume }\left(\mathrm{m}^{3}\right)\end{array}$ & $\begin{array}{l}\text { Reaction heat } \\
\text { (kcal/kgmole) }\end{array}$ & & \\
\hline & 0.0000 & 300 & 50.00 & 150.00 & $-2.4 \times 10^{4}$ & & \\
\hline \multirow[t]{2}{*}{$\begin{array}{l}\text { Top Product } \\
\text { Cooler (B4) }\end{array}$} & $\begin{array}{l}\text { Delta P } \\
\text { (bar) }\end{array}$ & Delta $\mathrm{T}\left({ }^{0} \mathrm{C}\right)$ & Duty (kcal/h) & & & & \\
\hline & 0.00 & -1027 & $1.865 \times 10^{6}$ & & & & \\
\hline \multirow[t]{2}{*}{$\begin{array}{l}\text { Product } \\
\text { Separator (B5) }\end{array}$} & $\begin{array}{l}\text { Condenser } \\
\text { pressure } \\
\text { (bar) }\end{array}$ & $\begin{array}{l}\text { Reboiler } \\
\text { pressure } \\
\text { (bar) }\end{array}$ & $\begin{array}{l}\text { External } \\
\text { Reflux ratio }\end{array}$ & $\begin{array}{l}\text { Internal } \\
\text { Reflux ratio }\end{array}$ & $\begin{array}{l}\text { Min. N0. of } \\
\text { Trays }\end{array}$ & $\begin{array}{l}\text { Max. N0. of } \\
\text { Trays }\end{array}$ & $\begin{array}{l}\text { Optima } \\
\text { feed stage }\end{array}$ \\
\hline & 1.00 & 1.00 & 3.50 & 2.530 & 4.278 & 8.549 & 5.849 \\
\hline \multirow[t]{2}{*}{$\begin{array}{l}\text { VCM rich } \\
\text { Heater (B6) }\end{array}$} & $\begin{array}{l}\text { Delta } \\
\text { (bar) }\end{array}$ & Delta $\mathrm{T}\left({ }^{0} \mathrm{C}\right)$ & Duty (kcal/h) & & & & \\
\hline & 0.00 & 41.60 & $4.157 \times 10^{5}$ & & & & \\
\hline \multirow[t]{3}{*}{$\begin{array}{l}\text { Pure VCM } \\
\text { Splitter }\end{array}$} & Products & $\begin{array}{l}\text { Vapour } \\
\text { Fraction }\end{array}$ & $\begin{array}{l}\text { Temperature } \\
\left({ }^{0} \mathrm{C}\right)\end{array}$ & Enthalpy & Pressure $(\mathrm{kPa})$ & & \\
\hline & Non VCM & 1.000 & 30.00 & $1.587 \times 10^{4}$ & 150.0 & & \\
\hline & Pure VCM & 1.000 & 30.00 & $8.375 \times 10^{3}$ & 311.1 & & \\
\hline \multirow[t]{2}{*}{ RCY-1 } & $\begin{array}{l}\text { Maximum } \\
\text { iteration }\end{array}$ & Flash Type & $\begin{array}{l}\text { Acceleration } \\
\text { Frequency }\end{array}$ & Q Maximum & Q Minimum & $\begin{array}{l}\text { Acceleration } \\
\text { Delay }\end{array}$ & \\
\hline & 10 & PT Flash & 3 & 0.00 & -20.00 & 2 & \\
\hline
\end{tabular}

Table 2.0: Experimental Design

\begin{tabular}{llll}
\hline Levels & -1 & 0 & 1 \\
\hline Flow rate of acetylene (A) (kgmole/hr) & 50 & 75 & 100 \\
\hline Flow rate of hydrogen chloride B (kgmole/hr) & 50 & 75 & 100 \\
\hline
\end{tabular}

\subsection{RESULTS AND DISCUSSION}

Experimental design was done using Factorial Method with two independent variables, each having three levels; and two response variables. The independent variables are the flow rates of acetylene and $\mathrm{HCl}$, while the response variables are the conversion of acetylene and $\mathrm{HCl}$. The factorial design method gives nine (9) experimental (simulation) runs for the simulation of the process, and the results obtained from the computer simulation of the integrated process route are shown in table 3.0:

Table 3.0: Hysys Simulation Results

\begin{tabular}{llll}
\hline Flow rate of Acetylene & Flow rate of $\mathrm{HCl}$ & Conversion of Acetylene & Conversion of $\mathrm{HCl}$ \\
\hline 0.0000 & 0.0000 & 90.0901 & 90.0996 \\
0.0000 & 1.0000 & 90.0905 & 67.854 \\
-1.0000 & 0.0000 & 90.0906 & 60.4425 \\
1.0000 & 0.0000 & 75.0751 & 100 \\
-1.0000 & 1.0000 & 90.0912 & 45.6163 \\
0.0000 & -1.0000 & 66.7333 & 100 \\
1.0000 & -1.0000 & 50.0500 & 100 \\
\hline
\end{tabular}


International Journal of Advances in Scientific Research and Engineering (ijasre), Vol 6 (12), December -2020

\begin{tabular}{llll}
\hline 1.0000 & 1.0000 & 90.0902 & 90.095 \\
-1.0000 & -1.0000 & 90.0902 & 90.0996
\end{tabular}

\subsection{Statistical Analysis of The Factorial Method}

Factorial method was used to model the relations between the different simulation variables and their outcome on the conversion of the reactants, based on the "Fit Regression Model" of MINITAB 17.0 (Pen, USA). The response variable was modeled through a polynomial model and analysis of variance (ANOVA) was done to assess the implication of each independent variable on conversion. Multiple regression analysis was used to develop a mathematical model that relates the simulated response to the independent variables. A general description for the Response is given by the polynomial model presented in (2):

$$
Y=\alpha_{0}+\sum_{i=1}^{n} \alpha_{i} X_{i}+\sum_{i=1}^{n} \alpha_{i i} X_{i}^{2}+\sum_{i=1}^{n-1} \sum_{j=i+1}^{n} \alpha_{i j} X_{i} X_{j}+\varepsilon
$$

Defining the terms in the model, $X_{1}, X_{2}, X_{3}, \ldots, X_{\mathrm{n}}$ are the predicting coded variables, $\alpha_{0}$ is the offset term, and $\alpha_{\mathrm{i}}$ accounts for the linear effects, $\alpha_{\mathrm{ii}}$ accounts for the squared effects and $\alpha_{\mathrm{ij}}$ accounts for the effects. The random error is denoted by $\varepsilon$. A model decrease may be convenient, if there are many redundant terms of the model [17]. The summary of the statistical model based on the Lack-of-Fit Test explicated the fitness of the models. The significance of each variable in the model was assessed using ANOVA and mathematical models were obtained based on the general response model of (2). The models obtained are (3) and (4), and were used for the prediction of the conversion (X) of acetylene and conversion (X) of hydrogen chloride, respectively. In these equations, the flow rates of acetylene and hydrogen chloride are represented as $\mathrm{A}$ and $\mathrm{B}$, respectively.

$$
\begin{aligned}
& X_{C_{2} H_{2}}(\%)=60.8-0.278 A+0.533 B \\
& X_{H C l}(\%)=84.3+0.537 A-0.538 B
\end{aligned}
$$

The ANOVA of the linear regression model showed the significant level of the model at $79.47 \%$ and $73.70 \%$ for the conversions of acetylene and hydrogen chloride, respectively (Tables 4.0 and 5.0). This reveals how better the model fits the simulation results. Hence, it infers that the total variance in the response could be described using this mathematical model. Results from regression analysis shows the statistical correlation and prominence between the independent variable and the response variable. $R^{2}$ is the correlation coefficient, which describes the percentage of conversion (\%) variation that is explained by its relationship with flow rates of acetylene and hydrogen chloride. So, the $R^{2}$ (adjusted) is percentage of conversion (\%) variation that is explained by its relationship with flow rates of acetylene and hydrogen chloride, adjusted for the number of independent variables in the model. This adjustment is vital since $R^{2}$ for this model increases when a new predictor is added. Hence, the adjusted $R^{2}$ is a valuable tool for comparing the explanatory strength of models with different predictors. The null hypothesis was tested using the Pvalues of 0.009 and 0.018 for each coefficient and indicates that the coefficient has no effect [17].

Table 4.0: Analysis of Variance for the conversion of Acetylene

\begin{tabular}{|l|l|l|l|l|l|}
\hline Source & DF & Adj SS & Adj MS & F-Value & P-Value \\
\hline Regression & 2 & 1343.96 & 671.978 & 11.62 & 0.009 \\
\hline Flow rate of Acetylene & 1 & 280.33 & 280.330 & 4.85 & 0.007 \\
\hline Flow rate of HCl & 1 & 838.75 & 838.749 & 14.50 & 0.009 \\
\hline Error & 6 & 347.12 & 57.854 & & \\
\hline Lack-of-Fit & 5 & 347.12 & 69.425 & $8.67811 \times 10^{8}$ & 0.000 \\
\hline Pure Error & 1 & 0.00 & 0.000 & & \\
\hline Total & 8 & 1691.08 & & & \\
\hline Model Summary & R-sq & R-sq (adj) & R-sq (Pred) & & \\
\hline S & $79.47 \%$ & $72.63 \%$ & $49.30 \%$ & & \\
\hline 7.60619 & \multicolumn{7}{l}{} \\
\hline Coefficients & \multicolumn{7}{|l|}{} \\
\hline
\end{tabular}


International Journal of Advances in Scientific Research and Engineering (ijasre), Vol 6 (12), December -2020

\begin{tabular}{|l|l|l|l|l|l|}
\hline Term & Coef & SE Coef & T-Value & P-Value & VIF \\
\hline Constant & 60.8 & 15.9 & 3.82 & 0.009 & \\
\hline Flow rate of Acetylene & -0.278 & 0.126 & -2.20 & 0.070 & 1.04 \\
\hline Flow rate of HCl & 0.533 & 0.140 & 3.81 & 0.009 & 1.04 \\
\hline
\end{tabular}

Table 5.0: Analysis of Variance for the conversion of $\mathrm{HCl}$

\begin{tabular}{|l|l|l|l|l|l|}
\hline Source & DF & Adj SS & Adj MS & F-Value & P-Value \\
\hline Regression & 2 & 2323.7 & 1161.84 & 8.41 & 0.018 \\
\hline Flow rate of Acetylene & 1 & 1043.1 & 11043.13 & 7.55 & 0.033 \\
\hline Flow rate of HCl & 1 & 853.0 & 853.00 & 6.17 & 0.048 \\
\hline Error & 6 & 829.3 & 138.22 & & \\
\hline Lack-of-Fit & 5 & 389.6 & 77.91 & 0.18 & 0.937 \\
\hline Pure Error & 1 & 439.8 & 439.77 & & \\
\hline Total & 8 & 3153.0 & & & \\
\hline Model Summary & R-sq & R-sq (adj) & R-sq (Pred) & & \\
\hline S & $73.70 \%$ & $64.93 \%$ & $36.76 \%$ & & \\
\hline 11.7568 & Coef & SE Coef & T-Value & P-Value & VIF \\
\hline Coefficients & 84.3 & 24.6 & 3.43 & 0.014 & \\
\hline Term & 0.537 & 0.195 & 2.75 & 0.033 & 1.04 \\
\hline Constant & -0.538 & 0.216 & -2.48 & 0.048 & 1.04 \\
\hline Flow rate of Acetylene &
\end{tabular}

\subsubsection{Graphical Representation of the Mathematical Model}

Figures 2.0 and 3.0 show the contour plots for the conversion of acetylene and conversion hydrogen chloride, respectively. This explore the potential relationship between independent variables (flow rate of acetylene \& flow rate of hydrogen chloride) and response variables (conversion of acetylene and conversion of hydrogen chloride). Hence, it displays the three-dimensional relationship in two dimensions, with $\mathrm{x}$ - and $\mathrm{y}$-factors (predictors) on the $\mathrm{x}$ - and $\mathrm{y}$-scales and response values represented by contours. From the legend of these plots, it is observed that maximum conversion of over $90 \%$ of both acetylene and hydrogen chloride is observed in a purple-colored region. 
International Journal of Advances in Scientific Research and Engineering (ijasre), Vol 6 (12), December -2020

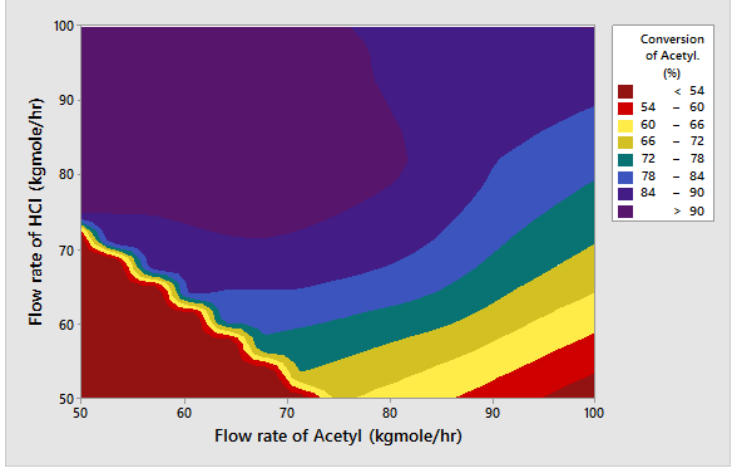

Figure 2.0: Contour plot for the conversion of Acetylene

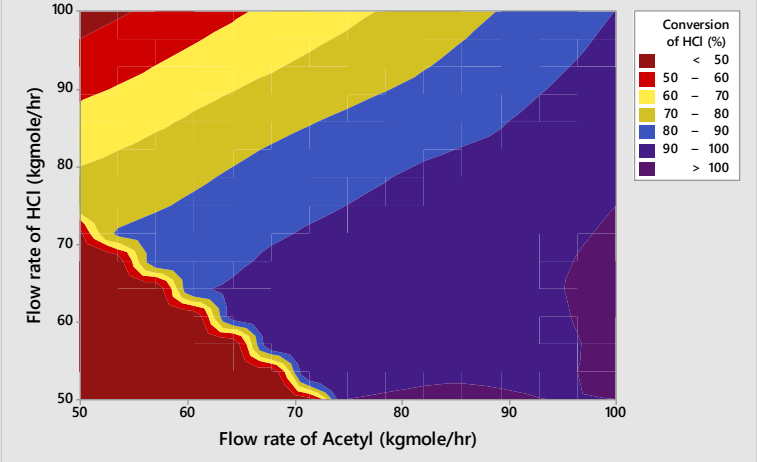

Figure 3.0: Contour plot for the conversion of $\mathrm{HCl}$

Figures 4.0 and 5.0 is the surface plots for the conversion of acetylene and conversion of Hydrogen chloride, respectively. This surface plots are generated from the full factorial design of the experiment. The 3D surface plots also showed how the conversion strongly rely on the flow rates of the reactants.

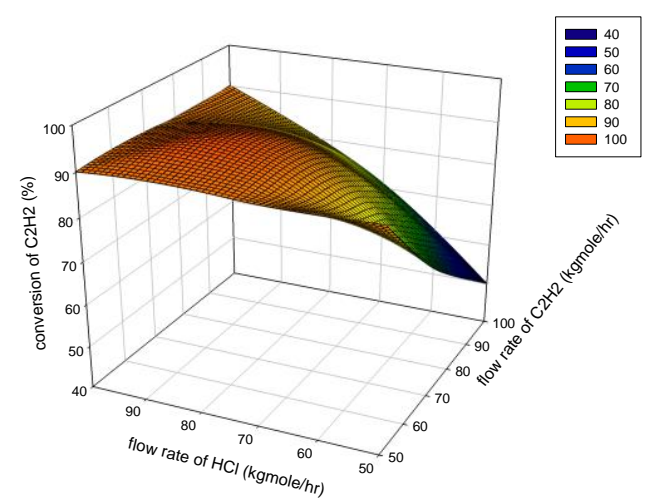

Figure 4.0: Surface plot for the conversion of Acetylene

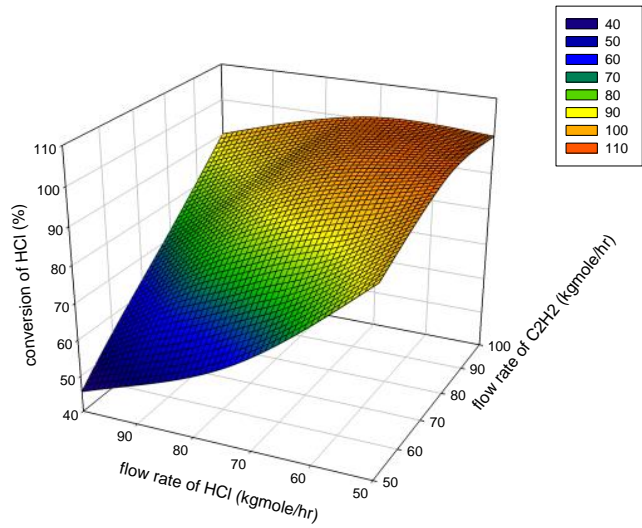

Figure 5.0: Surface plot for the conversion of $\mathrm{HCl}$

\subsection{Artificial Neural Network (ANN)}

Neural Builder (NB) of Artificial Intelligence Software, Neurosolutions 6.0 was used for the ANN modeling. Within the Neural network training environment, "Generalized feed forward" was adopted as the method of training and "Genetic Algorithm" as the input optimization. A hidden layer of 1 was used and this could train the simulation data better compared to higher values of hidden layers. Momentum value of 0.70 and step size of 0.1 was used as the learning rule, and selecting LinearTanhAxon as the transfer function for the ANN simulation. The Generalized ANN structure with 1 hidden layer for training the Hysys simulation results is presented in figure 6.0. 


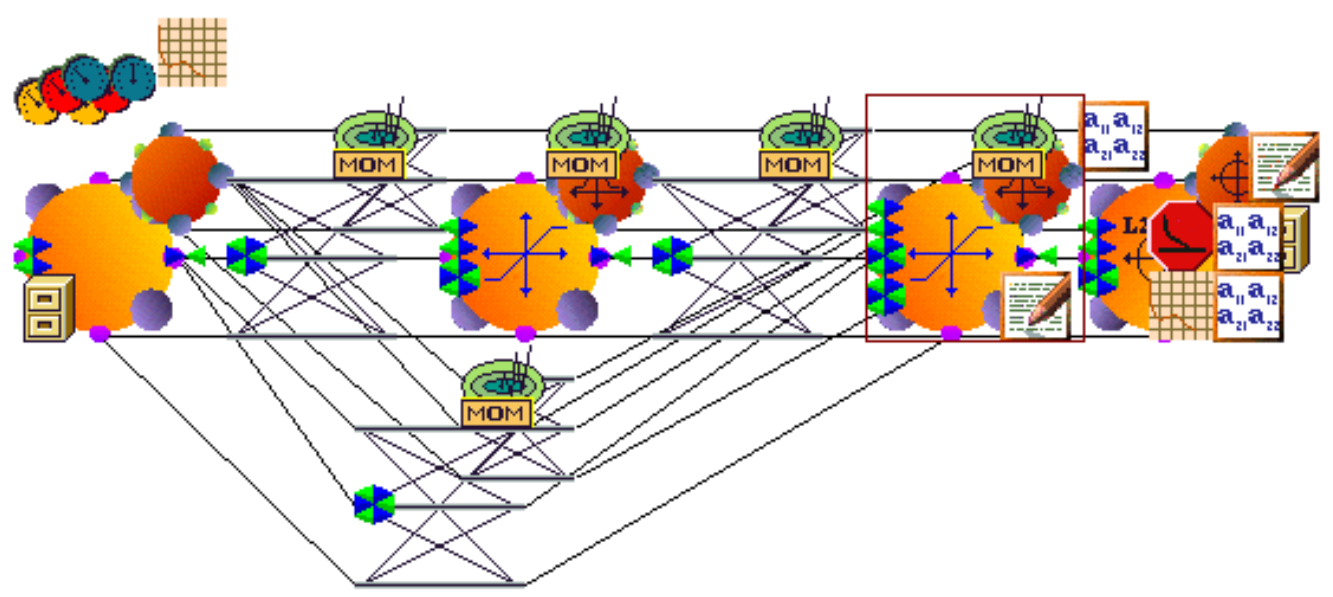

Figure 6.0: The Generalized NeuroBuilder for the ANN simulation

The Neural network simulation is completed at an epoch number of 245 while training the results for the conversion of acetylene and epoch number of 202 while training the results for the conversion of $\mathrm{HCl}$. The active performance for the ANN simulation is shown in table 6.0. The R squared values of the $97.921 \%$ and $98.423 \%$ for $\mathrm{X}_{\mathrm{C} 2 \mathrm{H} 2}$ and $\mathrm{X}_{\mathrm{HCl}}$, respectively as shown in ANN active performance results (Table 6.0) indicates the adequacy and better prediction of the ANN model. Also, the low values of the mean square error (MSE), normalized means square error (NMSE) and \% Error, indicates a slight variation which could be neglected while predicting the response variable. The "confusion matrix" is also identified as the "error matrix". It permits the visualization of the performance of the ANN algorithm with "true positive" value of 100, "true negative" value of 100, "false positive" value of 0 , and "false negative" value of 0 ,. The Accuracy, Precision and Recall values of the confusion matrix is found to be 1.0. Hence, it defines the performance of the model for which the actual values are known.

Table 6.0: ANN Active Performance

\begin{tabular}{|c|c|c|c|c|c|}
\hline \multicolumn{3}{|c|}{ ANN Active Performance for $\mathrm{X}_{\mathrm{C} 2 \mathrm{H} 2}$} & \multicolumn{3}{|c|}{ ANN Active Performance for $\mathrm{X}_{\mathrm{HCl}}$} \\
\hline MSE & \multicolumn{2}{|c|}{0.01898} & \multicolumn{2}{|c|}{ MSE } & 0.01904 \\
\hline NMSE & \multicolumn{2}{|l|}{0.04998} & \multicolumn{2}{|l|}{ NMSE } & 0.04498 \\
\hline R Square & \multicolumn{2}{|l|}{0.97921} & \multicolumn{2}{|l|}{ R Square } & 0.98423 \\
\hline$\%$ Error & \multicolumn{2}{|l|}{3.90714} & \multicolumn{2}{|l|}{$\%$ Error } & 4.94395 \\
\hline AIC & \multicolumn{2}{|l|}{12.3202} & \multicolumn{2}{|l|}{ AIC } & 16.3102 \\
\hline MDL & \multicolumn{2}{|l|}{-9.31312} & \multicolumn{2}{|l|}{ MDL } & -6.7364 \\
\hline \multicolumn{6}{|c|}{ ANN Active Confusion Matrix } \\
\hline & Positive & Negative & & Positive & Negative \\
\hline Positive & 100.0000 & 0.0000 & Positive & 100.0000 & 0.0000 \\
\hline Negative & 0.0000 & 100.000 & Negative & 0.0000 & 100.000 \\
\hline
\end{tabular}

Table 7.0 and 8.0 compares the predicting strength of the factorial method and artificial neural network. Solving the models shows the predicting values of each model. The strength of prediction of the Factorial Method and ANN model is best explained with their coefficient of determination ( $\mathrm{R}$ squared). The results shows that ANN with $\mathrm{R}$ squared values $97.921 \%$ and $98.423 \%$ for $\mathrm{X}_{\mathrm{C} 2 \mathrm{H} 2}$ and $\mathrm{X}_{\mathrm{HCl}}$, respectively could give better prediction of the Hysys simulation results compared to the factorial method with $\mathrm{R}$ squared values $79.47 \%$ and $73.70 \%$ for $\mathrm{X}_{\mathrm{C} 2 \mathrm{H} 2}$ and $\mathrm{X}_{\mathrm{HCl}}$, respectively. 
International Journal of Advances in Scientific Research and Engineering (ijasre), Vol 6 (12), December -2020

Table 7.0: Comparison of Factorial Method and ANN for the Conversion of Acetylene

\begin{tabular}{|l|l|l|l|l|}
\hline Flow rate of $\mathrm{C}_{2} \mathrm{H}_{2}$ & Flow rate of $\mathrm{HCl}$ & Hysys Simulation & Factorial Method & A.N.N modeling \\
\hline 0.0000 & 0.0000 & 90.0901 & 79.925 & 82.6711 \\
\hline 0.0000 & 1.0000 & 90.0905 & 93.25 & 92.3157 \\
\hline-1.0000 & 0.0000 & 90.0906 & 86.875 & 92.3157 \\
\hline 1.0000 & 0.0000 & 75.0751 & 72.975 & 67.3939 \\
\hline-1.0000 & 1.0000 & 90.0912 & 100.2 & 92.3157 \\
\hline 0.0000 & -1.0000 & 66.7333 & 66.6 & 70.9139 \\
\hline 1.0000 & -1.0000 & 50.0500 & 59.65 & $59 . .6925$ \\
\hline 1.0000 & 1.0000 & 90.0902 & 86.3 & 92.3157 \\
\hline-1.0000 & -1.0000 & 90.0902 & 73.55 & 92.3157 \\
\hline R Squared & & $79.49 \%$ & $97.921 \%$ \\
\hline
\end{tabular}

Table 8.0: Comparison of Factorial Method and ANN for the Conversion of $\mathrm{HCl}$

\begin{tabular}{|l|l|l|l|l|}
\hline Flow rate of $\mathrm{C}_{2} \mathrm{H}_{2}$ & Flow rate of $\mathrm{HCl}$ & Hysys Simulation & Factorial Method & A.N.N modeling \\
\hline 0.0000 & 0.0000 & 90.0996 & 84.225 & 73.1191 \\
\hline 0.0000 & 1.0000 & 67.854 & 70.775 & 74.5215 \\
\hline-1.0000 & 0.0000 & 60.4425 & 70.8 & 67.2060 \\
\hline 1.0000 & 0.0000 & 100 & 97.65 & 103.0213 \\
\hline-1.0000 & 1.0000 & 45.6163 & 57.35 & 60.1340 \\
\hline 0.0000 & -1.0000 & 100 & 97.675 & 93.1416 \\
\hline 1.0000 & -1.0000 & 100 & 111.11 & 93.3648 \\
\hline 1.0000 & 1.0000 & 90.095 & 84.2 & 86.6509 \\
\hline-1.0000 & -1.0000 & 90.0996 & 84.25 & 73.286 \\
\hline R Square & & $73.70 \%$ & $98.423 \%$ \\
\hline
\end{tabular}

\subsection{CONCLUSION}

Statistical analysis and modeling using full factorial and the Regression Fit Model of statistical analysis software, MINITAB 17.0 was carried out to assess the conversion of reactants from the simulation of an integrated process flow diagram for the synthesis of vinyl chloride monomer from acetylene with process simulation software, Aspen Hysys 8.8. Artificial Neural Network (ANN) of Neurosolutions 6.0 was also used to train and test the Aspen Hysys simulation results. The effect of molar flow rate of acetylene and $\mathrm{HCl}$ was examined while the conversion of the reactants was assessed by Factorial method and Artificial Neural Network. The process response variable (conversion) showed a stochastic distribution with respect to the predicting variables, with the maximum conversion of approximately $90 \%$ and $89 \%$ for acetylene and $\mathrm{HCl}$, respectively before a recycle unit is added; and maximum conversion of $99.90 \%$ and $99.89 \%$ for acetylene and $\mathrm{HCl}$, respectively after a recycle unit is added. sThis increase in the conversion after a recycle reveals that in chemical process, recycle units improves the performance of a process and there by optimize (increase) the results of an expected response. This shows a better and improved performance than the early study of [14] and conforms to the early study of [17]. The research work has revealed that the models used can be recommended for simulation and design of a pilot plant for the synthesis of Vinyl chloride monomer from acetylene. The model results reveals that ANN gives better model for prediction and analysis of the simulated process route with $\mathrm{R}$ squared values of $97.921 \%$ and $98.423 \%$ for the conversion of $\mathrm{C}_{2} \mathrm{H}_{2}$ and conversion of $\mathrm{HCl}$, respectively compared to $\mathrm{FM}$ with $\mathrm{R}$ squared values of $79.47 \%$ and $73.70 \%$ for the conversion of $\mathrm{C}_{2} \mathrm{H}_{2}$ and conversion of $\mathrm{HCl}$, respectively. 


\section{ACKNOWLEDGMENT}

The corresponding author is very thankful to DR. M.A. Usman of the Department of Chemical Engineering, University of Lagos, Akoka; Engr. M.O. Odunlami and Engr. O.M. Fadayini of the Department of Chemical Engineering, Lagos State Polytechnic, Ikorodu, Lagos, for their mentorship towards writing good research paper.

\section{REFERENCES}

[1] WHO Regional Office for Europe. (2010). Vinyl Chloride Air Quality Guidelines, second edition. Copenhagen, DenSmark.

[2] Criteria document over vinyl chloride. (1984). The Hague Ministerie van Volkshuisvesting, Ruimtelijke Ordening en Milieubeheer. (Publikatiereeks Lucht, No. 34.

[3] Naqvi, M. K., \& Kulshreshtha, A. K. (1995). Vinyl Chloride Manufacture: Technology Trends and an Energy Economic Perspective. Polymer-Plastics Technology 34 (2), 213-226.

[4] Bingham, D., Sitter, R., Kelly, E., Moore, L., \& Olivas, J. D. (2018). Factorial Designs With Multiple Levels of Randomnization. Statistica Sinica, 18, 493-513.

[5] Ihom, A., \& Offiong, A. (2015). NEURAL NETWORKS IN MATERIALS SCIENCE AND ENGINEERING: A REVIEW OF SALIENT ISSUES. European Journal of Engineering and Technology, $3(7), 40-54$.

[6] Ihom, A., \& Offiong, A. (2015). NEURAL NETWORKS IN MATERIALS SCIENCE AND ENGINEERING: A REVIEW OF SALIENT ISSUES. European Journal of Engineering and Technology, $3(7), 40-54$.

[7] Fausett, L. V. (1993). Fundamentals of Neural Networks (1st ed.). Newyork: Pearson Education.

[8] Awodele, O., \& Jegede, O. (2009). Neural Networks and Its Application in Engineering. Nigeria: InSITE.

[9] Kohli, S., Miglani, S., \& Rapariya, R. (2014). BASICS OF ARTIFICIAL NEURAL NETWORK. International Journal of Computer Science and Mobile Computing, 3(9), 745-751.

[10] Haykin, S. (1999). Neural networks: A comprehensive foundation (2nd ed.). Upper Saddle River, New Jersey: Prentice Hall.

[11] Babawuya, A., Osunde, Z. D., Sadiq, I. O., \& Eramus, C. U. (2014). Applications of Artificial Neural Network in Determining the Mechanical Properties of Melon Fruits. IOSR Journal of Agriculture and Veterinary Science, VI(6), 12-16.

[12] Shahin, M. A., Jaksa, M. B., \& Maier, H. R. (2004). Applications of Artificial Neural Networks in Foundation Egineering. Australia.

[13] Maier, H. R., \& Dandy, G. (2000, January). Application of Artificial Neural Networks to Forecasting of Surface Water Quality Variables: Issues, Applications and Challenges. 287-309. Netherland. Retrieved from https://www.researchgate.net/publication/228649194

[14] Akintola, J. T., Odunlami, M. O., Akintola, O. E., \& Abdulkareem, Y. T. (2020). Statistical Analysis and Optimization of the Synthesis of Vinyl Chloride from Acetylene via Simulation . International Journal of Latest Technology in Engineering, Management \& Applied Science (IJLTEMAS), Volume IX, Issue VIII, 6-13. 
[15] Fadayini, O., Madu, C., Oso, A., Ugba, E., Ajayi, S. J., \& Akintola, J. T. (2018). Simulation and Synthesis of Toluene by Dehydrogenation of N-heptane. Journal of Industrial Research and Technology, Vol. 7 No. 2, $110-120$.

[16] Amodu, O. S., Ntwampe, S. K., \& Ojumu, T. V. (2014). Optimization of biosurfactant production by Bacillus licheniformis STK 01 grown exclusively on Beta vulgaris waste using response surface methodology. BioResources, Vol. 9 (3), 5045-5065.

[17] Dattani, J., Devani, D., \& Sahu, O. (2013). Cleaner Production of Vinyl Chloride Monomer (VCM). International Journal of Scientific \& Engineering Research, Volume 4, Issue 5, 701-705. 